\title{
BOUNDS FOR SOME NEW INTEGRAL INEQUALITIES WITH DELAY ON TIME SCALES
}

\author{
TONGLin WANG AND RUN XU
}

Abstract. The purpose of this paper is to investigate some delay integral inequalities on time scales. Our results unify and extend some delay integral inequalities and their corresponding discrete analogues. The inequalities given here can be used as handy tools in the qualities theory of certain class of delay dynamic equations on time scales.

Mathematics subject classification (2010): 34C10.

Keywords and phrases: Integral inequalities, time scales, delay.

\section{REFERENCES}

[1] S. HILGER, Analysis on measure chains-a unified approach to continuous and discrete calculus, Results in Mathmatics 18, 1-2 (1990), 18-56.

[2] W. N. LI AND W. SHENG, Some nonliner integral inequalities on time scale, Journal of Inequalities and Applications 2007 (2007), Article ID 70465, 15 pages.

[3] M. Bohner, A. Peterson, Dynamic on Time Scales: An Introduction with Applications, Birkhäuser, Boston, 2001.

[4] M. Bohner And A. Peterson, Eds, Advances in Dynamic Equations on Time Scales, Birkhäuser, Boston, Mass, USA, 2003.

[5] W. N. Li And W. Sheng, Some nonliner dynamic inequalities on time scale, Proceedings of the Indian Academy of Science, Mathematical Sciences 117, 4 (2007), 545-554.

[6] F.-H. Wong, C.-C. YeH, AND C-H. Hong, Gronwall inequalities on time scales, Mathematical Inequalities and Applications 9, 1 (2006), 75-86.

[7] W. N. LI, Some delay integral inequalities on time scales, Computer and Mathematics with Applications 59 (2010), 1929-1936.

[8] W. N. LI, Bounds for Certain New Integral Inequalities on Time Scales, Advances in Difference Equations 2009 (2009), Article ID 484185, 16 pages.

[9] R. Xu And F. W. Meng, On Some Integral Inequalities on Time Scales and Their Applications, Journal of Inequalities and Applications 2010 (2010), Article ID 464976, 13 pages.

[10] D. B. PACHPATTE, Explicit estimates on integral inequalities with time scales, Journal of Inequalities in Pure and Applied Mathematics 7, 4 (2006), article 143.

[11] D. S. Mitrinovic, Analytic Inequalities, Springes, New York, NY, USA, 1970.

[12] Z. Yuan, X. Yuan, F. Meng, And H. Zhang, Some new delay integral inequalities and their applications, Applied Mathematics and Computation 208, 1 (2009), 231-237. 